\title{
Comparison of the epidemiology and co-morbidities of heart failure in the pediatric and adult populations: a retrospective, cross-sectional study Gregory Webster ${ }^{1}$, Jie Zhang ${ }^{2}$ and David Rosenthal*3
}

Address: ${ }^{1}$ Department of Pediatrics, University of California, San Francisco, CA, USA, ${ }^{2}$ Department of Statistics, Stanford University, Stanford, CA, USA and ${ }^{3}$ Department of Pediatrics, Stanford University, Stanford, CA, USA

Email: Gregory Webster - gregory_webster@yahoo.com; Jie Zhang - jiezhang00@yahoo.com; David Rosenthal* - davidnr@stanford.edu

* Corresponding author

Published: 25 May 2006

BMC Cardiovascular Disorders 2006, 6:23 doi:10.1186/147I-226I-6-23
Received: I4 December 2005

Accepted: 25 May 2006

This article is available from: http://www.biomedcentral.com/I47I-226I/6/23

(C) 2006 Webster et al; licensee BioMed Central Ltd.

This is an Open Access article distributed under the terms of the Creative Commons Attribution License (http://creativecommons.org/licenses/by/2.0), which permits unrestricted use, distribution, and reproduction in any medium, provided the original work is properly cited.

\begin{abstract}
Background: Heart failure is a clinical syndrome that is associated with a significant number of interventional procedures and has received a large amount of scrutiny in the adult literature; however, the epidemiology in children is less well described.

Methods: We analyzed two large, commercially available inpatient datasets collected in 1997 by the Agency for Healthcare Research and Quality: the Kids' Inpatient Database and the National Inpatient Study, accounting for $50 \%$ of the U.S. pediatric discharges and $20 \%$ of the U.S. adult discharges in 1997.

Results: The database contained 5,610 children and 732,752 adults with a diagnosis of HF. When compared with the adult sample, the pediatric sample showed a higher proportion with cardiac procedures $(6 I .4 \%$ vs. $0.28 \%, p<0.01)$, a higher prevalence of congenital heart disease $(61 \%$ versus $0.3 \%, p<0.01$ ), a higher percentage of male patients ( $50 \%$ pediatric vs. $44 \%$ adult, $p<0.0 \mathrm{I}$ ), and a lower percentage of white patients $(40.9 \%$ vs. $65.6 \%, p<0.01)$. Children had a significantly different spectrum of co-morbidities compared with adults. There was no difference in mortality rate between children and adults ( $7.5 \%$ vs. $7.9 \%, \mathrm{p}=\mathrm{NS})$.

Conclusion: There are significant differences in the epidemiological profile of children and adults with heart failure. Children suffer from different types of co-morbidities and require different procedures in the hospital setting. As such, children with heart failure who are hospitalized may require significantly different facilities, management and therapeutic intervention than adults with similar symptoms.
\end{abstract}

\section{Background}

Heart failure (HF) is a well-recognized clinical syndrome that affects both children and adults in the United States. HF in adults has received considerable attention, with multiple large, randomized trials that have evaluated the etiology and therapy of this condition. For example, the
Framingham Heart Study has tracked data on adult cardiac disease since 1948 and numerous more recent trials have evaluated specific therapies for systolic dysfunction [1-12]. However, the pediatric population is more difficult to study. It is difficult to enroll large numbers of children in prospective studies, consent is more challenging 
to obtain and the definition of suitable endpoints remains challenging.

Previous studies in children such as the 1985 BaltimoreWashington Infant Study have described the incidence of congenital heart disease, but have not focused on heart failure [13]. Recently the Prospective Pediatric Cardiomyopathy Registry reported on the incidence of pediatric cardiomyopathy (but not HF) in 2 regions of the United States, suggesting an incidence of 1.13 cases per 100,000 children [14]. A population-based study conducted in Finland over a longer time frame ( 11 years) had similar findings [15]. However, heart failure due to other therapies (chemotherapy-induced damage, or heart failure due to congenital heart disease) was specifically excluded and likely comprises a major component of pediatric HF [16]. Other studies of pediatric HF or cardiomyopathy have had a limited sample size or have been from limited geographic regions [17-19].

The annual incidence of dilated cardiomyopathy in adults is 2 to 8 cases per 100,000 in the US and Europe. The prevalence in adults in 1992 was estimated at 26 individuals per 100,000 members of the population [20].

We are not aware of any comparisons between the characteristics of adults with HF and children with HF. There are no reports of complicating co-morbidities in these two populations and the underlying prevalence of HF in these populations has not been compared. Given the importance of understanding the differences between these populations, we have examined a national database compiled over one calendar year containing both pediatric and adult admissions. From this database, we have taken all known cases of heart failure and detailed the co-morbidities associated with the diagnosis, the types of procedures that those patients receive, the length that they stay in the hospital setting and the outcome of their hospital stays. In doing so, we have highlighted some of the differences between the adult and pediatric population with heart failure.

\section{Methods \\ Design and setting}

We used two datasets in this study: the Kids' Inpatient Database (KID) and the National Inpatient Study (NIS). Both are commercially available datasets compiled by the Agency for Healthcare Research and Quality (AHRQ) as part of the Healthcare Utilization Project (HCUP). Both databases are subsets of the same larger project. The data were gathered and coded with identical methods. The KID is a pediatric database that is culled from a larger dataset that represents those admissions from 0 to 18 years of age. The KID and NIS are nationwide databases that contain inpatient stay information collected from hospital dis- charge records. Both databases cover the calendar year 1997. These records are maintained by hospitals, state agencies, and other private data organizations. These data were collected from all discharges by each hospital, compiled by state data organizations and edited and checked by AHRQ. Full documentation for the NIS and KID databases is available through HCUP [21,22].

\section{Patients and hospitals}

The 1997 KID contains approximately 1.9 million pediatric discharges, representing approximately $50 \%$ of the pediatric discharges in the United States for the year 1997. It includes data from 22 states. The 1997 NIS contains approximately 7.1 million discharges of all ages from over 1,000 hospitals, containing approximately $20 \%$ of adult discharges in the United States for the year 1997.

In both datasets, the included hospitals range from major teaching hospitals to community hospitals. Both datasets include information on all patients, regardless of payer, including those covered by Medicaid, private insurance and the uninsured. Data is grouped into over 100 categories, covering both clinical and non-clinical information. All data files contained a principal diagnosis as coded by the physician or staff member at discharge as well as up to 14 additional diagnoses for each case. All data files contained up to 15 procedure codes, identified by ICD-9-CM code.

\section{Data collection}

Diagnoses consistent with heart failure were identified using the International Classification of Disease code (ICD-9-CM). We included ICD-9 codes 398.91 (rheumatic heart failure, congestive); 402.01, 402.11, and 402.91 (hypertensive heart disease with congestive heart failure); 404.01, 404.11, 404.91, 404.03, 404.13, and 404.93 (hypertensive heart and renal disease with congestive heart failure); 428.xx (congestive heart failure); and 429.4 (cardiac failure following surgery, excluding immediate postoperative failure [997.1]). Each diagnostic code was converted to a diagnostic category based on the Clinical Classification Software (CCS) available from the HCUP website. After the initial selection by ICD-9 code, all subsequent analysis was based on these CCS codings. Relevant procedures were identified using the CCS. Full documentation on CCS has been described by HCUP previously [23].

\section{Analysis}

The population was divided into three groups, those under one year of age (infants), those between one and 18 years of age (children), and those over 18 years of age (adults). These criteria were chosen prior to analysis based on the clinical observation that the etiology of heart failure differs before and after one year of age [14]. Where the 
two pediatric groups were not significantly different, the results were pooled to simplify presentation of the data. Cases were analyzed for the number of co-morbid diagnoses in each group. Co-morbid diagnoses were divided into system-based categories and all CCS diagnostic codes were assigned to a system-based category by the authors.

The CCS procedure codes were similarly divided by the authors into system-based categories with a large "miscellaneous" category that contained both non-classifiable procedures and those procedures that were classifiable into multiple system-based categories.

Chi square analysis was utilized to compare the adult and pediatric populations in all categorical variables. Sub-testing was done using the Yates correction and the Bonferroni inequality was used to allow for the fact that multiple comparisons were being done. For continuous variables, ANOVA testing was used.

\section{Results and discussion}

We identified 5,610 people 18 years old or less and 732,752 people greater than 18 years old with heart failure. In our sample population, 3,176 children were younger than one year of age (infants). HF was the primary diagnosis in 564 infants (18\%) and was a secondary diagnosis in 2,612 infants (82\%). There were 2,434 patients between one year and 18 years of age (children). HF was the primary diagnosis in 614 children (25\%) and was a secondary diagnosis in the remaining 1,820 children (75\%).

The data on gender are summarized in Table 1. Unlike in older patients, where there is a substantial over-representation of female patients, we find that children have a nearly identical proportion of male and female patients.

The pediatric sample (ages 0-18) had a significantly greater percentage of non-white patients when compared to their adult counterparts (Table 2). However, in both pediatric and adult groups, whites make up the greatest number overall, followed by blacks and then Hispanics. Note that the numbers do not sum to $100 \%$ since not all patients in the database were assigned a code for race at the time of discharge.
Pediatric hospital length of stay was appreciably longer than adults, with infants having the longest stays (Table 3 ). The presence or absence of heart failure as a primary diagnosis did not reliably predict length of stay across the three groups.

Many patients were also documented as having important co-morbidities. As would be expected, the incidence of congenital cardiac disease was greater in both infants and children when compared with the adult population. However, there was a striking decrease in the incidence of congenital cardiac disease in children when compared with infants, which may be due to the likelihood of having congenital defects repaired in infancy, reducing the likelihood of hospitalization due to left to right shunting lesions. Infants and children have a high incidence of non-cardiac congenital lesions. The other identified diagnostic categories are summarized in Table 4.

The frequency of cardiac procedures is shown in Table 5. Pediatric patients have a higher proportion of cardiac bypass procedures when compared with adult patients. This underscores the high prevalence of surgical management for serious structural problems in pediatrics. The rates of intubation are significantly higher in pediatrics than in adults, which probably reflects the increased prevalence of surgical management in pediatrics. In addition, cardiac transplantation, while infrequent in all age groups, was significantly more common in children than in adults.

Not surprisingly, stays that required the use of cardioversion were associated with increased risk of mortality in all age groups. Findings for intubation were similar. These data are shown in Table 6.

There was no difference in overall mortality between children and adults $(7.5 \%$ vs. $7.9 \%, \mathrm{p}=\mathrm{NS})$, which is probably a serendipitous finding given the significant differences in etiologies, co-morbidities, and treatment approaches between the two groups.

We describe here differences between pediatric and adult heart failure patients in the hospital setting. It is challenging to gather pediatric data that can be directly compared

Table I: Gender Comparison

\begin{tabular}{llc}
\hline Age Group & Male & Gender (\%) \\
\hline Age $0-18$ & $2792(49.8)$ & Female \\
Age $>18$ & $323972(44.2)$ & $408737(55.8)$ \\
\hline P-value & $<0.01$ & $<0.01$ \\
\hline
\end{tabular}


Table 2: Racial Demographics

\begin{tabular}{|c|c|c|c|c|c|c|c|}
\hline \multirow[b]{2}{*}{ Age Group } & \multirow[b]{2}{*}{ White } & \multirow[b]{2}{*}{ Non-white } & \multicolumn{5}{|c|}{ Races comprising Non-white Category } \\
\hline & & & Black & Hispanic & $\begin{array}{r}\text { Asian/Pacific } \\
\text { Islander }\end{array}$ & $\begin{array}{r}\text { Native } \\
\text { American }\end{array}$ & Other \\
\hline Age $0-18$ & 2295 (40.9) & $1970(35.1)$ & $797(14.2)$ & $757(13.5)$ & $178(3.2)$ & $28(0.5)$ & $210(3.7)$ \\
\hline Age $>18$ & $480867(65.6)$ & $111624(15.2)$ & $69520(9.5)$ & $29980(4.1)$ & $5488(0.7)$ & $766(0.1)$ & $5870(0.8)$ \\
\hline P-value & $<0.01$ & $<0.01$ & & & & & \\
\hline
\end{tabular}

Note: numbers in parenthesis represent $\%$ of total population in each age range

against adult data since almost all large trials have been exclusively in the adult population. We have explored a single database, designed for financial data gathering; and, from there, we have extracted relevant clinical information to compare the two populations. Since it is only in the last several years that data of this type have been made available, this has rarely been done previously and never in HF to our knowledge.

Clear differences exist between pediatric and adult HF patients. The overall difference between the numbers of procedures that children undergo versus adults is striking. A likely cause for this difference is the discrepancy between the frequencies of congenital heart disease in the two populations. Our study supports the observation that congenital heart disease is a common causative factor in pediatric heart failure, while it is a much less common reason for HF in adults. As the number of adults with repaired congenital heart disease increases, the number of cases of HF in adults due to congenital heart disease will also increase, but our data suggest that - despite this anticipated growth - congenital heart disease is not likely to become a common cause of HF in adults.

In addition, the prevalence of other congenital anomalies (including non-cardiac) is higher in hospitalized children than in hospitalized adults. There are three reasons that may account for this observation. First, patients with other congenital disorders may have excess childhood mortality and would therefore not be included in adult samples. In addition, there may be a recording bias toward classifying problems as congenital by the physicians who care for children. Finally, coronary artery disease is a major cause of $\mathrm{HF}$ and subsequent hospitalization in adults but it is rare in children, and this etiology is presumably not related to the presence of congenital anomalies.

Our study suggests that there are other significant differences between children and adults with HF. Adults are significantly more likely to have neurological, hematological and oncologic, infectious disease, renal and endocrine abnormalities, suggesting that adults are often sick with multi-system disease that may not be directly linked to the etiology of their heart failure. However, the association between HF and other congenital diseases in children suggests that children may be more likely to have syndromic conditions that influence their outcome. Further study is necessary to determine what percentage of children and adults have significant mortality due to those co-morbidities.

While in the hospital, children were significantly more likely than adults to undergo intubation, cardiac bypass, cardioversion and other cardiac procedures. Hospital stays were significantly longer in the pediatric population, perhaps due to the surgical management of major structural anomalies. In contrast, adults with HF experienced a low utilization of intubation, cardiac bypass and other cardiac procedures, suggesting that the major components of their regimen were medical, as opposed to surgical, therapies.

A major limitation of our study lies in the fact that we had access only to a large, commercially available dataset. Therefore, it was impossible to correlate specific diagnoses with chart review since we had no access to individual patient documentation. Similarly, since the dataset was

Table 3: Age and Length of Stay

\begin{tabular}{ll}
\hline Age (years) & Length of Stay (days) \\
\hline $0-1$ & $15.52^{*}$ \\
$\geq 1$ and $\leq 18$ & $11.1^{*}$ \\
$>18$ & $7.43^{*}$ \\
\hline
\end{tabular}

* All comparisons $\mathrm{p}<0.01$ versus the other two comparison groups. 
Table 4: Subspecialty Comorbid Diagnoses

\begin{tabular}{|c|c|c|c|c|c|}
\hline \multirow[b]{2}{*}{ Diagnosis } & \multicolumn{3}{|c|}{ Percent of patients with diagnosis } & \multirow[b]{2}{*}{$\begin{array}{l}\text { Infants vs. Children p- } \\
\text { value* }\end{array}$} & \multirow[b]{2}{*}{$\begin{array}{l}\text { Pediatric vs. Adult } \mathrm{P}^{-} \\
\text {value }^{+}\end{array}$} \\
\hline & Age $<$ I yr & Age $\geq I \mathrm{yr}$ and $\leq 18 \mathrm{yr}$ & Age $>18 \mathrm{yr}$ & & \\
\hline Congenital, Cardiac & $82.27 \%$ & $34.26 \%$ & $0.28 \%$ & $<0.01$ & $<0.01$ \\
\hline $\begin{array}{l}\text { Congenital, Non- } \\
\text { cardiac }\end{array}$ & $30.64 \%$ & $14.46 \%$ & $0.36 \%$ & $<0.01$ & $<0.01$ \\
\hline Neurological & $8.25 \%$ & $21.2 \%$ & $34.13 \%$ & $<0.01$ & $<0.01$ \\
\hline $\begin{array}{l}\text { Hematological/ } \\
\text { Oncologic }\end{array}$ & $14.29 \%$ & $25.84 \%$ & $31.38 \%$ & $<0.01$ & $<0.01$ \\
\hline Infectious Diseases & $33.56 \%$ & $36.11 \%$ & $47.64 \%$ & 0.05 & $<0.01$ \\
\hline Pulmonary & $30.2 \%$ & $35.09 \%$ & $22.87 \%$ & $<0.01$ & $<0.01$ \\
\hline Rheumatology & $0.38 \%$ & $2.44 \%$ & $7.13 \%$ & $<0.01$ & $<0.01$ \\
\hline Ophthalmology & $2.15 \%$ & $3.23 \%$ & $5.53 \%$ & $<0.01$ & $<0.01$ \\
\hline Orthopedics & $1.75 \%$ & $6.53 \%$ & $17.13 \%$ & $<0.01$ & $<0.01$ \\
\hline Otolaryngology & $3.83 \%$ & $4.73 \%$ & $2.02 \%$ & 0.14 & $<0.01$ \\
\hline $\begin{array}{l}\text { Obstetrics and } \\
\text { Gynecology }\end{array}$ & $0.10 \%$ & $2.59 \%$ & $1.16 \%$ & $<0.01$ & $<0.01$ \\
\hline Renal & $8.45 \%$ & $18.93 \%$ & $30.88 \%$ & $<0.01$ & $<0.01$ \\
\hline Endocrine & $19.08 \%$ & $20.05 \%$ & $26.73 \%$ & $<0.01$ & $<0.01$ \\
\hline Gastroenterological & $3.83 \%$ & $4.72 \%$ & $2.02 \%$ & 0.37 & $<0.01$ \\
\hline
\end{tabular}

* Infants vs. children comparison is between infants (age $<1 \mathrm{yr}$ ) and children (ages $\geq I$ year and $\leq 18$ years)

+ Pediatric vs. adult comparison is between all infants and children (age $>0$ and $\leq 18$ years) and all adults (age $>18$ years)

primarily designed for utilization analysis, we were unable to further subdivide the operative procedures into subcategories that would allow us to describe specific interventions. However, the benefit of using a large, if categorically limited, dataset is that it allows us a well-powered study. This study indicates that the significant differences in interventions in patients with heart failure suggest that the etiology, and therefore subsequent care, of children's heart failure differ significantly between children and adults.

\section{Conclusion}

We have found that significantly different interventions are utilized for children and adults in the hospital setting. As such, children with heart failure who are hospitalized may require significantly different facilities, management and therapeutic intervention than adults with similar symptoms. Given the high rate of procedural interventions for children with congestive heart failure, close collaboration between cardiologists and cardiothoracic surgeons is imperative to optimize care for these children.

\section{Competing interests}

The author(s) declare that they have no competing interests.

\section{Authors' contributions}

GW participated in the design and coordination of the study, participated in the statistical analysis and drafted the manuscript. JZ was responsible for the primary statistical analysis. DR conceived of the study concept, participated in the design, reviewed the statistical analysis and edited the manuscript. All authors read and approved the final manuscript. GW received support for this work from

Table 5: Procedural Comparison

\begin{tabular}{lcccc}
\hline & Age $<1$ yr & $\begin{array}{c}\text { Percent of patients undergoing procedure } \\
\text { Age } \geq I \text { yr and } \leq 18 \text { yr }\end{array}$ & Age $>18$ yr & P-value* \\
\hline All Procedures & $82.2 \%$ & $34.2 \%$ & $0.3 \%$ & $<0.01$ \\
- Intubation & $28.2 \%$ & $14.9 \%$ & $6.9 \%$ & $<0.01$ \\
- Cardiac Bypass & $25.9 \%$ & $16.2 \%$ & $2.6 \%$ & $<.01$ \\
- Cardioversion & $2.2 \%$ & $2.6 \%$ & $1.8 \%$ & $<.01$ \\
- Cardiac & $0.5 \%$ & $3.3 \%$ & $0.1 \%$ & $<1$ \\
Transplantation & & $34.3 \%$ & $0.3 \%$ & $<.01$ \\
- Other Cardiac & $82.3 \%$ & & & \\
Procedure & & & & \\
\hline
\end{tabular}

$*$ P-value is due to variability between pediatric patients (age $0-18$ years) and adults (age $>18$ years). 
Table 6: Mortality Comparison by Procedure

\begin{tabular}{|c|c|c|c|c|c|c|}
\hline & \multicolumn{2}{|c|}{ Mortality (\%) } & \multirow[b]{2}{*}{$\mathrm{P}$-value } & \multicolumn{2}{|c|}{ Mortality (\%) } & \multirow[b]{2}{*}{ P-value } \\
\hline & $\begin{array}{l}\text { With } \\
\text { Cardioversion }\end{array}$ & $\begin{array}{l}\text { Without } \\
\text { Cardioversion }\end{array}$ & & With Intubation & $\begin{array}{l}\text { Without } \\
\text { Intubation }\end{array}$ & \\
\hline Age $<$ I yr. & 47.1 & 6.3 & $<0.01$ & 15.8 & 3.8 & $<0.01$ \\
\hline $\begin{array}{l}\text { Age } \geq 1 \text { and } \leq 18 \\
\text { yrs. }\end{array}$ & 48.4 & 6.7 & $<0.01$ & 23.8 & 5.0 & $<0.01$ \\
\hline Age > 18 yrs. & 36.5 & 6.8 & $<0.01$ & 36.3 & 5.8 & $<0.01$ \\
\hline
\end{tabular}

the Stanford University Medical Scholars Award for Biomedical

Research.

\section{Acknowledgements}

Stanford University was the primary funding source for all authors.

\section{References}

I. Effects of enalapril on mortality in severe congestive heart failure: Results of the Cooperative North Scandinavian Enalapril Survival Study (CONSENSUS). The CONSENSUS Trial Study Group. N Engl J Med 1987, 3 I 6: |429-| 435.

2. The SOLVD Investigators: Effect of enalapril on survival in patients with reduced left ventricular ejection fractions and congestive heart failure. N Engl J Med I99I, 325:293-302.

3. Cohn JN, Johnson G, Ziesche S, Cobb F, Francis G, Tristani F, Smith $R$, Dunkman WB, Loeb $H$, Wong $M$, et al.: A comparison of enalapril with hydralazine-isosorbide dinitrate in the treatment of chronic congestive heart failure. $N$ Engl J Med 1991, 325:303-310.

4. The SOLVD Investigators: Effect of enalapril on mortality and the development of heart failure in asymptomatic patients with reduced left ventricular ejection fractions. $N$ Engl J Med 1992, 327:685-69|.

5. Packer M, Colucci WS, Sackner-Bernstein JD, Liang CS, Goldscher DA, Freeman I, Kukin ML, Kinhal V, Udelson JE, Klapholz M, Gottlieb SS, Pearle D, Cody RJ, Gregory IJ, Kantrowitz NE, Lejemtel TH, Young ST, Lukas MA, Shusterman NH: Double-blind, placebocontrolled study of the effects of carvedilol in patients with moderate to severe heart failure. The PRECISE Trial. Prospective Randomized Evaluation of Carvedilol on Symptoms and Exercise. Circulation 1996, 94:2793-2799.

6. Bristow MR, Gilbert EM, Abraham WT, Adams KF, Fowler MB, Her shberger RE, Kubo SH, Narahara KA, Ingersoll H, Krueger S, Young $\mathrm{S}$, Shusterman N: Carvedilol produces dose-related improvements in left ventricular function and survival in subjects with chronic heart failure. MOCHA Investigators. Circulation 1996, 94:2807-28|6.

7. Colucci WS, Packer M, Bristow MR, Gilbert EM, Cohn JN, Fowler MB, Krueger SK, Hershberger R, Uretsky BF, Bowers JA, Sackner-Bernstein JD, Young ST, Holcslaw TL, Lukas MA: Carvedilol inhibits clinical progression in patients with mild symptoms of heart failure. US Carvedilol Heart Failure Study Group. Circulation 1996, 94:2800-2806.

8. Pitt B, Zannad F, Remme WJ, Cody R, Castaigne A, Perez A, Palensky J. Wittes J: The effect of spironolactone on morbidity and mortality in patients with severe heart failure. Randomized Aldactone Evaluation Study Investigators. N Engl J Med 1999 34I:709-7I 7.

9. Hjalmarson A, Goldstein S, Fagerberg B, Wedel $H$, Waagstein $F$, Kjekshus J, Wikstrand J, El Allaf D, Vitovec J, Aldershvile J, Halinen M, Dietz R, Neuhaus KL, Janosi A, Thorgeirsson G, Dunselman PH, Gullestad L, Kuch J, Herlitz J, Rickenbacher P, Ball S, Gottlieb S, Deedwania P: Effects of controlled-release metoprolol on total mortality, hospitalizations, and well-being in patients with heart failure: the Metoprolol CR/XL Randomized Intervention Trial in congestive heart failure (MERIT-HF). MERITHF Study Group. Jama 2000, 283: | 295-I302.

10. Packer M, Coats AJ, Fowler MB, Katus HA, Krum H, Mohacsi P Rouleau JL, Tendera M, Castaigne A, Roecker EB, Schultz MK
DeMets DL: Effect of carvedilol on survival in severe chronic heart failure. N Engl J Med 200I, 344: |65 I- I658.

II. Kenchaiah S, Narula J, Vasan RS: Risk factors for heart failure. Med Clin North Am 2004, 88(5): I I 45-I I 72.

12. Schellenbaum GD, Rea TD, Heckbert SR, Smith NL, Lumley T, Roger VL, Kitzman DW, Taylor HA, Levy D, Psaty BM: Survival associated with two sets of diagnostic criteria for congestive heart failure. Am J Epidemiol 2004, I60(7):628-635

13. Ferencz C, Rubin JD, McCarter RJ, Brenner JI, Neill CA, Perry LW, Hepner SI, Downing JW: Congenital heart disease: prevalence at livebirth. The Baltimore-Washington Infant Study. Am J Epidemiol 1985, I 2 I(I):31-36.

14. Lipshultz SE, Sleeper LA, Towbin JA, Lowe AA, Orav EJ, Cox GF, Lurie PR, McCoy KL, McDonald MA, Messere JE, Colan SD: The incidence of pediatric cardiomyopathy in two regions of the United States. N Engl J Med 2003, 348: |647-I655.

15. Arola A, Jokinen E, Ruuskanen O, Saraste M, Pesonen E, Kuusela AL, Tikanoja T, Paavilainen T, Simell O: Epidemiology of idiopathic cardiomyopathies in children and adolescents - a nationwide study in Finland. Am J Epidemiol 1997, I46:385-93.

16. Boucek MM, Edwards LB, Keck BM, Trulock EP, Taylor DO, Hertz MI: Registry for the International Society for Heart and Lung Transplantation: seventh official pediatric report - 2004 . Heart Lung Transplant 2004, 23(8):933-947.

17. Chen SC, Nouri S, Balfour I, Jureidini S, Appleton RS: Clinical profile of congestive cardiomyopathy in children. I Am Coll Cardiol 1990, I 5(I): I89-193.

18. Bilgic A, Ozbarlas N, Ozkutlu S, Ozer S, Ozme S: Cardiomyopathies in children. Clinical, epidemiological and prognostic evaluation. Jpn Heart J 1990, 3 I(6):789-797.

19. Nugent AW, Daubeney PE, Chondros P, Carlin JB, Cheung M, Wilkinson LC, Davis AM, Kahler SG, Chow CW, Wilkinson JL, Weintraub RG: The epidemiology of childhood cardiomyopathy in Australia. N Engl J Med 2003, 348(I 7): I639-I646.

20. Manolio TA, Baughman KL, Rodenheffer R, Pearson TA, Bristow JD, Michels VV, Abelmann WH, Harlan WR: Prevalence and etiology of dilated cardiomyopathy. Am J Cardiol 1992, 69:|458-|466.

21. 1997 NIS Technical Documentation. July 2000. Agency for Healthcare Research and Quality, Rockville, MD [http:// www.hcup-us.ahrq.gov/db/nation/nis/nisdbdocumentation.jsp]

Publish with Bio Med Central and every scientist can read your work free of charge

"BioMed Central will be the most significant development for disseminating the results of biomedical research in our lifetime. "

Sir Paul Nurse, Cancer Research UK

Your research papers will be:

- available free of charge to the entire biomedical community

- peer reviewed and published immediately upon acceptance

- cited in PubMed and archived on PubMed Central

- yours - you keep the copyright
BioMedcentral 
22. KID Technical Documentation. December 200I. Agency for Healthcare Research and Quality, Rockville, MD [http:// www.hcup-us.ahrq.gov/db/nation/kid/kiddbdocumentation.jsp]

23. Clinical Classifications Software. Fact Sheet. Agency for Healthcare Research and Quality, Rockville, MD [http:// www.hcup-us.ahrq.gov/toolssoftware/ccs/ccsfactsheet.jsp]

\section{Pre-publication history}

The pre-publication history for this paper can be accessed here:

http://www.biomedcentral.com/1471-2261/6/23/prepub

Publish with Bio Med Central and every scientist can read your work free of charge

"BioMed Central will be the most significant development for disseminating the results of biomedical research in our lifetime. " Sir Paul Nurse, Cancer Research UK

Your research papers will be:

- available free of charge to the entire biomedical community

- peer reviewed and published immediately upon acceptance

- cited in PubMed and archived on PubMed Central

- yours - you keep the copyright

Submit your manuscript here:

http://www.biomedcentral.com/info/publishing_adv.asp 